Int. J. Electrochem. Sci., 15 (2020) $1498-1508$

\title{
Solid octahedral NiO micro-particles prepared by a calcination method in the presence of an ionic liquid and their application as anode for lithium ion batteries
}

\author{
Xuan Zhang ${ }^{1}$, Keqiang Ding ${ }^{1,2, *}$ Xiaojing Gao $^{2}$, Xiaomi Shi ${ }^{2}$, Jingwei Han ${ }^{2}$, Junqing Pan ${ }^{1, *}$ \\ ${ }^{1}$ State Key Laboratory of Chemical Resource Engineering, Beijing University of Chemical \\ Technology, Beijing, 100029, P.R.China \\ ${ }^{2}$ College of Chemistry and Materials Science, Hebei Normal University, Shijiazhuang 050024, P.R. \\ China \\ *E-mail: dkeqiang@263.net (K. Ding.); jqpan@mail.buct.edu.cn (J. Pan)
}

doi: $10.20964 / 2020.02 .36$

Received: 5 August 2019 / Accepted: 30 September 2019 / Published: 31 December 2019

\begin{abstract}
A novel finding, that solid octahedral $\mathrm{NiO}$ micro-particles can be prepared via an ionic liquid (IL)present calcination method using nickel acetate as the starting material, was reported for the first time in this communication. In the absence of IL, NiO particles with a porous cauliflower-like morphology were produced. The crystal structure and the morphologies of all synthesized samples were respectively characterized by using X-ray diffraction (XRD) and scanning electron microscopy (SEM). The formation of $\mathrm{NiO}$ phase in sample a was further verified via HRTEM and XPS. Also, it was revealed by the galvanostatic charge-discharge measurement that the initial discharge capacity of the solid octahedral $\mathrm{NiO}$ micro-particles was $757.3 \mathrm{mAh} \mathrm{g}^{-1}$ at $100 \mathrm{~mA} \mathrm{~g}^{-1}$, much larger than that of sample $\mathrm{b}\left(436.3 \mathrm{mAh} \mathrm{g}^{-1}\right)$. And even after 50 cycles, the discharge capacities of all prepared samples were all maintained higher than $210 \mathrm{mAh} \mathrm{g}^{-1}$ at $100 \mathrm{~mA} \mathrm{~g}$. The successful preparation of solid octahedral $\mathrm{NiO}$ micro-particles was very favorable not only for the development of lithium ions anode materials but also for the exploration of micro-scale devices.
\end{abstract}

Keywords: solid octahedral $\mathrm{NiO}$; microstructure; calcination; ionic liquid; energy storage and conversion.

\section{FULL TEXT}

(C) 2020 The Authors. Published by ESG (www.electrochemsci.org). This article is an open access article distributed under the terms and conditions of the Creative Commons Attribution license (http://creativecommons.org/licenses/by/4.0/). 